\title{
Adult BMI and fat distribution but not height amplify the effect of low birthweight on insulin resistance and increased blood pressure in 20-year-old South Africans
}

Received: 25 June 2004 / Accepted: 14 December 2004 / Published online: 29 April 2005

(C) Springer-Verlag 2005

\begin{abstract}
Aims/hypothesis: We examined whether associations between low birthweight and adult chronic cardiometabolic disease were dependent upon birthweight alone, or on interactions with BMI, fat accumulation either generally or abdominally, or attained height in young South African adults. Methods: Blood pressure (BP), lipids, glucose tolerance, insulin sensitivity and secretion (homeostasis model) were measured in 20-year-olds $(n=132)$ born at full term and with birthweights on or below the tenth centile (underweight for gestational age [UFA]) or between the 25th and 75th centiles for gestational age (appropriate weight for gestational age, [AFA]). Sex-specific median measurements of BMI, waist circumference, percentage body fat and height defined current anthropometric status,
\end{abstract}

N. S. Levitt

Department of Medicine, Faculty of Health Sciences,

University of Cape Town,

Observatory,

Cape Town, South Africa

E. V. Lambert

Department of Human Biology, Faculty of Health Sciences,

University of Cape Town,

Cape Town, South Africa

D. Woods

Department of Neonatal Medicine, Faculty of Health Sciences, University of Cape Town,

Cape Town, South Africa

\section{J. R. Seckl}

Molecular Medicine Centre, University of Edinburgh,

Edinburgh, Scotland, UK

C. N. Hales

Department of Clinical Biochemistry, University of Cambridge,

Cambridge, UK

N. S. Levitt $(\bowtie)$

Department of Medicine, (J47 Old Main Building),

Groote Schuur Hospital, Observatory,

Cape Town, 7925, South Africa

e-mail: dinky@uctgsh1.uct.ac.za

Tel.: +27-21-4045007

Fax: $+27-21-4486815$ providing four groups for each measure: UFA-low or UFAhigh and AFA-low or AFA-high. Results: The UFA-high BMI group was more insulin-resistant than both low BMI groups $(p<0.04)$, but not the AFA-high BMI group. In contrast, plasma triglycerides and systolic BP were higher in the UFA-high than in all other groups (all $p<0.04$ ). When characterised by body fatness, both high percentage (\%) body fat groups had higher fasting [insulin] than low percentage $(\%)$ body fat groups $(p<0.03)$, and higher [total cholesterol] and [LDL cholesterol] than the UFA-low percentage $(\%)$ body fat group $(p<0.05)$. The UFA-high group had higher systolic and diastolic BP than all other groups (all at least $p<0.03$ ). A similar pattern was observed when groups were characterised by waist circumference; however, current height status had no effect. Conclusions/ interpretation: These data indicate that the "fetal origins" expression of the chronic disease phenotype is not dependent on birthweight alone, but on its interaction with subsequent fat accumulation, though not on attained height, in this cohort of young adults.

Keywords Blood pressure - Catch-up growth - Glucose tolerance $\cdot$ Insulin resistance $\cdot$ Low birthweight $\cdot$ Obesity

Abbreviations AFA: appropriate for gestational age · BP: blood pressure - HOMA: homeostasis - UFA: underweight for gestational age

\section{Introduction}

Extensive epidemiological data show that low birthweight is associated with an increased incidence or risk of chronic cardiovascular and metabolic disorders in adulthood, notably hypertension, glucose intolerance, diabetes and coronary heart disease [1-7]. Although the relevance of this to industrialised societies, where low birthweight is becoming less common, has recently been questioned, it remains pertinent in transitional societies where the prevalence of adult cardio-metabolic diseases is rising steeply and where low birthweight remains common. 
South Africa is such an example. Indeed in the community of mixed ancestral origin, the prevalence of diabetes is $10 \%$ [8], hypertension $18 \%$ [9] and low birthweight $14 \%$ [10]. Furthermore, an association between low birthweight and higher systolic and diastolic blood pressures (BP) and fasting blood glucose concentrations, but not measures of insulin sensitivity or secretion, has been reported in 20year-old adults [11]. These observations, made in the absence of centralisation of body fat stores or frank obesity in the low-birthweight group, are of interest, as recently consideration has been given to the potential interaction between low birthweight and subsequent growth or the presence of obesity in the development of these adultonset chronic diseases [4, 12-25]. A number of studies have reported that features of the chronic disease phenotype have been accentuated or amplified in the presence of postnatal or childhood skeletal catch-up growth [17, 19, 22, 24], although this has not been a universal finding. A positive association between skeletal catch-up growth and systolic BP was reported in all three studies in which this was examined in children, adolescents and adults [6].

An interaction between birthweight and subsequent skeletal growth as well as current obesity has also been described for insulin resistance, systolic BP and serum cholesterol in 8 -year-old Indian children [17, 19]. Adult obesity increased the risk for type 2 diabetes in a low-birthweight cohort [12]. Further, subsequent growth or weight accrual, which cannot be described as catch up, but rather is defined by a high BMI later in life or relative change in weight from birth to current weight, has been positively associated with systolic $\mathrm{BP}$ in 11 of 13 studies in a recent systematic review [6]. Data from longitudinal studies have recently emphasised the importance of adiposity rebound, but not height in the development of the chronic disease phenotypes [20, 23, 25]. Thus, skeletal catch up and subsequent fat accumulation can be argued to be modulators of the expression of the "fetal origins" of chronic disease.

We examined whether the association between low birthweight and this chronic disease phenotype was dependent upon birthweight alone or upon an interaction between birthweight and the subsequent accrual of weight for height, the accumulation of fat either generally or abdominally, or attained height in young disadvantaged South African adults.

\section{Subjects, materials and methods}

As the detailed methods of this study have been reported previously [11], they will only be summarised here.

Subjects Singleton infants $(n=1,077)$ born at full term (3741 weeks) to primigravid women of mixed ancestry in the Groote Schuur Hospital Maternity Centre in 1975 and 1976 and with a birthweight on or below the tenth centile (underweight for gestational age [UFA]; $n=231$ ) or between the 25th and 75th centiles for gestational age (appropriate weight for gestational age, $[\mathrm{AFA}] ; n=846$ ) were eligible for the study. The current sample consisted of a random sample of 133 AFA boys and 146 AFA girls drawn from the 846 AFA births and all 231 UFA children. Each infant's record of gestational age [26], birthweight, length, head circumference, placental weight, ponderal index, maternal age, height and in most cases, maternal post-delivery weight, was available. We attempted to track these individuals at the age of 20 years by means of maternal hospital records, their hospital records and the voters roll.

We traced 166 of the 510 subjects. The low recovery rate is attributable to socio-political factors, in particular the forced dislocation of entire neighbourhoods, combined, in many cases, with the difficulty of tracing the offspring of single mothers. Those traced were invited to participate in the study, which was approved by the University of Cape Town Ethics and Research Committee. The participants provided signed consent.

Protocol The subjects (aged 20 years) and mothers or primary care-givers were interviewed to obtain data on maternal health, socio-economic status at the time of pregnancy and the participants' current socio-demographic and health status. Socio-economic status at birth was assessed on the basis of parental education and housing density at that stage.

The subjects attended the clinical research centre after an overnight fast and the following investigations were carried out: anthropometry, BP, fasting serum lipid profile and oral glucose tolerance tests (75 g glucose monohydrate in $250 \mathrm{ml}$ of water). Blood glucose concentrations were measured at $0,30,60,90$ and $120 \mathrm{~min}$, insulin at 0 , 30 and $120 \mathrm{~min}$ and pro-insulin, 32/33 split pro-insulin and lipid concentrations were measured at $0 \mathrm{~min}$. Blood for glucose estimations was collected in tubes containing fluoride. All samples were kept on ice, centrifuged and the plasma stored at $-20^{\circ} \mathrm{C}$ until assayed.

Height, weight, waist circumference and four skinfold sites were measured, i.e. triceps, biceps, subscapular and supra-iliac folds were measured as previously described [11]. The sum of the skinfold measurements was used to calculate percentage of body fat according to the equation of Durnin and Wormersley [27].

After at least $20 \mathrm{~min}$ at rest, BP was measured three times at 5-min intervals using an appropriately sized cuff and a Space Labs 90207 ambulatory BP monitor. An average of the last two readings was used in the analyses.

Insulin resistance was examined using the homeostasis (HOMA) model [28]: fasting insulin, pro-insulin and 32/33 split pro-insulin concentrations [29]. Insulin secretion was assessed using the 30-min insulin increment to the 30-min glucose increment [29] and HOMA model for beta cell function [28]. Fasting total immunoreactive insulin (sum of specific serum insulin, pro-insulin and $32 / 33$ split proinsulin) was used in the HOMA model.

Laboratory methods Plasma glucose was measured by the glucose oxidase method on a Beckman auto-analyzer (Beckman Instruments, Fullerton, CA, USA). Plasma total cholesterol, HDL cholesterol, and triglyceride concentrations were measured enzymatically using standard methods (Hitachi 911 auto-analyzer, Boehringer Mannheim, Germany). 
LDL cholesterol was calculated from total cholesterol, HDL cholesterol, and triglycerides using the Friedewald Equation. Serum insulin, pro-insulin and split pro-insulin were measured by specific immunometric assays in Cambridge, UK [30].

Statistical analysis In an attempt to differentiate the effects of birthweight alone compared to the interaction between birthweight and subsequent growth and development, we conducted various analyses, comparing four phenotype groups, in each instance. Subjects were grouped, firstly according to birthweight category as UFA or AFA, and subsequently, according to the sex-specific median value for both groups combined, for each of four anthropometric measures, namely BMI, height, percentage of body fat and waist circumference (Table 1). These are referred to as, for example, UFA-low-height and UFA-high-height, with respect to birthweight and the current anthropometric indices.

For most of the variables, the study was adequately statistically powered, based on the results of similar studies, such as that of Leger et al. [31]. For example, in order to show differences in 120-min plasma insulin of $3 \mathrm{pmol} / 1$ with a standard deviation of $2.1 \mathrm{pmol} / \mathrm{l}$, we required seven subjects per group to achieve an alpha level of 0.05 , and $80 \%$ power.

The results are expressed as means $\pm \mathrm{SD}$, if the variable measured was normally distributed. Plasma glucose, serum insulin, pro-insulin and split pro-insulin concentrations, HOMA IR and HOMA $\beta$ were not normally distributed and were $\log$ transformed prior to analysis. These data are subsequently presented as medians and upper and lower quartiles within the tables. Significant differences between groups were examined using analysis of variance, covarying for sex, and Fisher's least squares differences post hoc analyses were conducted where significant $F$-ratios were found. Repeated measures analyses of variance were used for the OGTT also co-varying for sex, and where $F$-ratios were significant, a Tukey's HSD post-hoc analysis was conducted. An alpha level of $<0.05$ was considered to be statistically significant.

\section{Results}

We traced 166 of the 510 subjects initially identified, of whom 29 refused to participate. The proportion of UFA subjects traced was higher than that of AFA subjects (32 vs $23 \%$ ). The gestational ages (UFA 39.3 \pm 0.9 , AFA $39.1 \pm 2$

Table 1 Median (and lower and upper quartile) values for BMI, height, waist and per cent (\%) body fat

\begin{tabular}{cclll}
\hline & BMI $\left(\mathrm{kg} / \mathrm{m}^{2}\right)$ & Height $(\mathrm{m})$ & Body fat $(\%)$ & Waist $(\mathrm{cm})$ \\
\hline Men & 20.6 & 1.71 & 18.8 & 72.9 \\
$(n=63)$ & $(19.4,22.3)$ & $(1.65,1.76)$ & $(15.9,21.4)$ & $(69,78.8)$ \\
Women & 22.9 & 1.58 & 30.0 & 71.8 \\
$(n=74)$ & $(20.7,25.3)$ & $(1.54,1.62)$ & $(26.2,33.0)$ & $(65.5,77.6)$ \\
\hline
\end{tabular}

weeks), ponderal indices $\left(24.9 \pm 2.1,25.6 \pm 1.1 \mathrm{~kg} / \mathrm{m}^{3}\right)$ and sex ratios ( $48 \%$ men, $52 \%$ women) were similar in those taking part and those not, suggesting that selection bias was not a contributing factor in these analyses. Complete data were available in 113 subjects (59 AFA; 54 UFA) and incomplete data (excluding lipids and glucose tolerance) in a further 24 (14 AFA; ten UFA; total 137). This represented a $26.7 \%$ recovery rate.

Interaction between birthweight and current BMI We initially examined the interaction between birthweight and current BMI, as a measure of acquired weight for height, when comparing current anthropometry, glucose tolerance data, plasma lipid concentrations and BP in the four phenotype groups: UFA-low BMI, UFA-high BMI, AFA-low BMI, and AFA-high BMI. The results of these analyses are presented in Table 2 .

There were no differences in blood glucose concentrations at any time point, nor in plasma insulin concentrations at 0 and $30 \mathrm{~min}$, fasting pro-insulin, split pro-insulin concentrations, HOMA $\beta$ or total cholesterol, HDL cholesterol and LDL cholesterol concentrations or diastolic BP between any of the birthweight and BMI groups. Conversely, the UFA-high BMI group had a significantly higher HOMAIR $(p<0.04)$ than both low-BMI groups and higher 120-min plasma insulin concentrations compared to the UFA-low BMI, only $(p<0.002)$. Plasma triglycerides and systolic BP were significantly higher in the UFA-high BMI group compared to all other groups $(p<0.04)$.

In summary, the UFA-high BMI group presented with more adverse metabolic sequelae than the UFA-low BMI and AFA-low BMI groups. The UFA-high BMI group, however, was largely indistinguishable from the AFA-high BMI group, with the exception of systolic BP and plasma triglyceride concentrations.

Generalised body fatness and features of metabolic syndrome: interaction with birthweight We next addressed whether the expression of the features of the metabolic syndrome found in the UFA-high BMI group were dependent on generalised fatness. Indirect evidence was provided by current anthropometry in the high-BMI groups, who were significantly fatter $(p<0.05)$, irrespective of birthweight groups. In this instance, we compared glucose tolerance data, plasma lipid concentrations and BP in four phenotype groups on the basis of body fatness (above and below the median percentage of fat): UFA-low percentage of body fat, UFA-high percentage of body fat, AFA-low percentage of body fat, and AFA-high percentage of body fat (Table 3).

Plasma glucose levels, HOMA IR, HOMA $\beta$, plasma pro-insulin, 32/33 split pro-insulin, 30- and 120-min insulin concentrations, serum triglycerides and HDL cholesterol were similar in all four groups. In contrast, fasting insulin concentrations were significantly higher in both high percentage of body fat than both low percentage body fat groups (all at least $p<0.05$ ). Total cholesterol and LDL cholesterol concentrations were higher in both high per- 
Table 2 Plasma glucose, insulin and pro-insulin concentrations, measures of beta cell function, insulin resistance, lipids and BP by birthweight and current BMI groups

\begin{tabular}{|c|c|c|c|c|}
\hline & UFA-low BMI $(n=35)$ & UFA-high BMI $(n=21)$ & AFA-low BMI $(n=16)$ & AFA-high BMI $(n=31)$ \\
\hline \multicolumn{5}{|l|}{ Glucose (mmol/l) } \\
\hline $0 \mathrm{~min}$ & $4.9 \pm 0.5$ & $4.9 \pm 0.4$ & $4.7 \pm 0.5$ & $4.7 \pm 0.4$ \\
\hline $30 \min$ & $7.2 \pm 1.5$ & $7.6 \pm 1.9$ & $6.9 \pm 1.4$ & $7.1 \pm 1.3$ \\
\hline $60 \min$ & $6.7 \pm 2.4$ & $7.5 \pm 2.2$ & $6.5 \pm 2.1$ & $6.9 \pm 1.7$ \\
\hline $90 \min$ & $6.0 \pm 2.1$ & $6.1 \pm 1.7$ & $5.6 \pm 1.2$ & $6.2 \pm 1.3$ \\
\hline $120 \mathrm{~min}$ & $5.4 \pm 1.6$ & $6.1 \pm 1.5$ & $5.5 \pm 1.2$ & $5.5 \pm 1.1$ \\
\hline \multicolumn{5}{|l|}{ Insulin $(\mathrm{pmol} / \mathrm{l})$} \\
\hline $0 \mathrm{~min}$ & $28.0(20.0 ; 39.0)$ & $52.0(33.0 ; 75.5)$ & $35.0(19.0 ; 48.0)$ & $36.0(26.0 ; 61.0)$ \\
\hline $30 \min$ & $309.0(176.0 ; 415.0)$ & $492.0(218.0 ; 827.0)$ & $293.0(175.0 ; 608.0)$ & $408.0(225.0 ; 550.0)$ \\
\hline $120 \mathrm{~min}$ & $195.5(100.0 ; 314.0)$ & $422.5(193.5 ; 669.0)^{\mathrm{a}}$ & $249.5(160.5 ; 429.5)$ & $339.0(148.5 ; 517.0)$ \\
\hline Pro-insulin (pmol/l) & $3.9(2.5 ; 4.8)$ & $5.1(2.6 ; 6.7)$ & $3.5(2.3 ; 5.2)$ & $4.3(2.7 ; 5.4)$ \\
\hline 32/33 PI (pmol/l) & $6.5(4.1 ; 8.6)$ & $9.8(4.2 ; 13.0)$ & $6.0(2.8 ; 7.4)$ & $8.3(5.5 ; 9.3)$ \\
\hline HOMA $\beta$ & $59.4(40.6 ; 92.8)$ & $105.0(65.0 ; 160.6)$ & $75.8(61.2 ; 97.8)$ & $95.5(53.8 ; 148.5)$ \\
\hline HOMA IR & $1.1(0.6 ; 1.5)$ & $1.8(1.1 ; 2.7)^{\mathrm{b}}$ & $1.1(0.6 ; 1.7)$ & $1.3(0.9 ; 2.3)$ \\
\hline Triglycerides $(\mathrm{mmol} / \mathrm{l})$ & $0.6 \pm 0.2$ & $0.9 \pm 0.6^{\mathrm{c}}$ & $0.7 \pm 0.3$ & $0.7 \pm 0.2$ \\
\hline Total cholesterol (mmol/l) & $3.9 \pm 0.7$ & $4.5 \pm 1.1$ & $4.3 \pm 1.3$ & $4.4 \pm 0.8$ \\
\hline LDL cholesterol (mmol/1) & $2.4 \pm 0.7$ & $2.9 \pm 1.0$ & $2.8 \pm 1.3$ & $2.9 \pm 0.7$ \\
\hline HDL cholesterol $(\mathrm{mmol} / \mathrm{l})$ & $1.2 \pm 0.3$ & $1.1 \pm 0.3$ & $1.2 \pm 0.2$ & $1.2 \pm 0.3$ \\
\hline Systolic BP (mmHg) & $123.6 \pm 11.1$ & $130.3 \pm 16.0^{\mathrm{c}}$ & $118.6 \pm 10.4$ & $124.0 \pm 12.1$ \\
\hline Diastolic BP (mmHg) & $71.1 \pm 7.8$ & $74.3 \pm 9.4$ & $68.6 \pm 9.0$ & $70.0 \pm 8.6$ \\
\hline
\end{tabular}

Values are means \pm SD or median (upper; lower quartiles)

${ }^{\mathrm{a}} p=0.002$ for UFA-high BMI vs UFA-low BMI

${ }^{\mathrm{b}} p<0.04$ for UFA-high vs both low BMI groups

${ }^{c} p<0.04$ for UFA-high BMI vs all other groups

centage of fat groups than in the UFA-low percentage of body fat group only (both at least $p<0.002$ for total cholesterol and $p<0.001$ for LDL cholesterol). The UFA- high percentage of body fat group had significantly higher levels of systolic and diastolic BP than the other three groups (all at least $p=0.03$ ).

Table 3 Plasma glucose, insulin and pro-insulin concentrations, measures of beta cell function, insulin resistance, lipids and BP by birthweight and current percentage $(\%)$ of fat groups

\begin{tabular}{|c|c|c|c|c|}
\hline & $\begin{array}{l}\text { UFA-low percentage } \\
(\%) \text { of body fat }(n=34)\end{array}$ & $\begin{array}{l}\text { UFA-high percentage } \\
(\%) \text { of body fat }(n=23)\end{array}$ & $\begin{array}{l}\text { AFA-low percentage } \\
(\%) \text { of body fat }(n=14)\end{array}$ & $\begin{array}{l}\text { AFA-high percentage } \\
(\%) \text { of body fat }(n=33)\end{array}$ \\
\hline Fasting blood glucose $(\mathrm{mmol} / \mathrm{l})$ & $4.9 \pm 0.5$ & $4.9 \pm 0.4$ & $4.7 \pm 0.5$ & $4.7 \pm 0.4$ \\
\hline \multicolumn{5}{|l|}{ Insulin (pmol/l) } \\
\hline $0 \mathrm{~min}$ & $26.5(18.5 ; 40.5)^{\mathrm{a}}$ & $48.0(32.0 ; 75.0)$ & $30.0(17.5 ; 46.0)^{\mathrm{a}}$ & $36.0(27.0 ; 67.0)$ \\
\hline $30 \min$ & $309.5(187.0 ; 436.0)$ & $423.0(220.0 ; 714.0)$ & $192.0(167.0 ; 614.5)$ & $413.0(315.0 ; 574.5)$ \\
\hline $120 \mathrm{~min}$ & $190.0(100.0 ; 278.0)$ & $388.5(201.0 ; 656.0)$ & $205.0(156.0 ; 445.0)$ & $339.0(163.0 ; 517.0)$ \\
\hline Pro-insulin (pmol/1) & $3.9(2.5 ; 4.9)$ & $4.8(2.2 ; 6.5)$ & $3.7(2.4 ; 5.3)$ & $3.9(2.7 ; 5.4)$ \\
\hline 32/33 PI (pmol/l) & $5.8(3.9 ; 8.5)$ & $9.8(4.9 ; 13.0)$ & $6.9(3.3 ; 8.9)$ & $8.0(5.0 ; 9.3)$ \\
\hline HOMA $\beta$ & $58.7(39.6 ; 97.1)$ & $88.5(56.4 ; 156.5)$ & $75.8(52.2 ; 102.7)$ & $89.4(63.6 ; 147.5)$ \\
\hline HOMA IR & $0.9(0.6 ; 1.5)$ & $1.7(1.1 ; 2.7)$ & $1.1(0.5 ; 1.9)$ & $1.3(0.9 ; 2.0)$ \\
\hline Triglycerides (mmol/l) & $0.66 \pm 0.27$ & $0.85 \pm 0.60$ & $0.76 \pm 0.32$ & $0.66 \pm 0.18$ \\
\hline Total cholesterol (mmol/1) & $3.8 \pm 0.2^{\mathrm{c}}$ & $4.6 \pm 0.2$ & $4.0 \pm 0.3$ & $4.5 \pm 0.2$ \\
\hline LDL cholesterol (mmol/l) & $2.3 \pm 0.6^{\mathrm{c}}$ & $3.1 \pm 0.9$ & $2.5 \pm 0.7$ & $3.0 \pm 1.0$ \\
\hline HDL cholesterol (mmol/1) & $1.2 \pm 0.3$ & $1.1 \pm 0.3$ & $1.2 \pm 0.2$ & $1.2 \pm 0.3$ \\
\hline Systolic BP (mmHg) & $123.1 \pm 11.0$ & $130.4 \pm 15.2^{\mathrm{b}}$ & $120.0 \pm 11.3$ & $124.0 \pm 11.7$ \\
\hline Diastolic BP (mmHg) & $70.3 \pm 7.8$ & $75.3 \pm 8.4^{\mathrm{b}}$ & $69.1 \pm 8.2$ & $70.3 \pm 9.0$ \\
\hline
\end{tabular}

Values are means \pm SD or median (upper; lower quartiles)

${ }_{p} p<0.05$ for both high percentage $(\%)$ of fat groups vs both low percentage (\%) of body fat groups

${ }^{\mathrm{b}} p<0.03$ for UFA-high percentage (\%) of fat group vs all other groups

${ }^{c} p<0.002$ for UFA-low percentage (\%) of body fat vs UFA-high percentage (\%) of body fat and AFA-high percentage (\%) of body fat 
Table 4 Plasma glucose, insulin and pro-insulin concentrations, measures of beta cell function, insulin resistance, lipids and BP by birthweight and current waist circumference groups

\begin{tabular}{|c|c|c|c|c|}
\hline & UFA-low waist $(n=35)$ & UFA-high waist $(n=22)$ & AFA-low waist $(n=14)$ & AFA-high waist $(n=33)$ \\
\hline Fasting blood glucose $(\mathrm{mmol} / \mathrm{l})$ & $4.8 \pm 0.5$ & $4.9 \pm 0.4$ & $4.7 \pm 0.5$ & $4.7 \pm 0.4$ \\
\hline \multicolumn{5}{|l|}{ Insulin $(\mathrm{pmol} / \mathrm{l})$} \\
\hline $0 \mathrm{~min}$ & $25.0(17.5 ; 39.5)$ & $48.0(36.0 ; 75.0)^{\mathrm{a}}$ & $35.0(19.0 ; 41.0)$ & $36.0(26.0 ; 67.0)$ \\
\hline $30 \min$ & $306.0(176.0 ; 423.0)$ & $486.0(220.0 ; 736.0)$ & $293.0(175.0 ; 727.0)$ & $408.0(225.0 ; 528.0)$ \\
\hline $120 \mathrm{~min}$ & $201.0(100.0 ; 346.0)$ & $337.5(163.0 ; 615.0)$ & $336.5(179.5 ; 483.5)$ & $232.5(121.0 ; 473.0)$ \\
\hline Pro-insulin (pmol/l) & $3.8(2.3 ; 4.5)$ & $5.5(2.7 ; 6.8)$ & $3.9(2.7 ; 5.3)$ & $4.3(2.6 ; 5.4)$ \\
\hline 32/33 PI (pmol/1) & $5.5(3.9 ; 8.1)$ & $10.0(4.3 ; 13.0)$ & $6.4(3.4 ; 7.6)$ & $8.3(5.0 ; 9.3)$ \\
\hline HOMA $\beta$ & $56.9(38.3 ; 92.8)$ & $92.6(74.5 ; 156.5)$ & $72.5(61.2 ; 96.6)$ & $95.3(59.8 ; 147.5)$ \\
\hline HOMA IR & $0.9(0.5 ; 1.5)$ & $1.8(1.3 ; 2.7)^{\mathrm{a}}$ & $1.1(0.6 ; 1.6)$ & $1.3(0.9 ; 2.3)$ \\
\hline Triglycerides (mmol/l) & $0.61 \pm 0.21$ & $0.92 \pm 0.61^{\mathrm{b}}$ & $0.67 \pm 0.26$ & $0.70 \pm 0.21$ \\
\hline Total cholesterol (mmol/1) & $3.9 \pm 0.7$ & $4.4 \pm 1.1$ & $4.2 \pm 1.2$ & $4.5 \pm 0.8$ \\
\hline LDL cholesterol (mmol/l) & $2.4 \pm 0.7^{\mathrm{c}}$ & $2.9 \pm 1.0$ & $2.6 \pm 1.3$ & $3.0 \pm 0.7$ \\
\hline HDL cholesterol (mmol/l) & $1.2 \pm 0.3$ & $1.1 \pm 0.3$ & $1.2 \pm 0.2$ & $1.2 \pm 0.3$ \\
\hline Systolic BP (mmHg) & $123.9 \pm 10.5$ & $131.0 \pm 15.7^{\mathrm{b}}$ & $120.1 \pm 10.5$ & $123.7 \pm 12.2$ \\
\hline Diastolic BP (mmHg) & $70.8 \pm 7.8$ & $74.8 \pm 8.8$ & $70.1 \pm 8.6$ & $69.7 \pm 8.8$ \\
\hline
\end{tabular}

Values are means \pm SD or median (upper; lower quartiles)

${ }_{p}<0.04$ for UFA-high waist vs UFA-low waist and AFA-low waist

${ }^{\mathrm{b}} p<0.04$ for UFA-high waist vs all other groups

${ }^{c} p<0.04$ for UFA-high and AFA-high waist groups vs UFA-low waist group

Body fat distribution and features of metabolic syndrome: interaction with birthweight We then assessed whether centralisation of body fat stores resulted in similar metabolic sequelae to those associated with generalised body fatness. When the groups were analysed by waist circumferences, the anthropometric patterns were similar to those observed when the phenotypes were defined by percentage of body fatness. Thus, BMI was significantly higher in the high-waist groups compared to the low-waist groups, irrespective of birthweight $(p<0.005)$ (Table 4).

Blood glucose concentrations at all time points, insulin concentrations at 30 and $120 \mathrm{~min}$, total cholesterol, HDL cholesterol, diastolic BP and HOMA $\beta$ did not differ between any of the groups. The UFA-high waist group had significantly higher HOMA IR and fasting insulin concentrations than both the low-waist groups (all at least $p<0.04$ ), but these measures were similar in the two high-waist groups. Systolic BP and serum triglycerides were significantly higher in the UFA-high waist group compared to the other three groups (all at least $p<0.04$, respectively). Furthermore, LDL cholesterol levels were higher in both high-waist groups than in the UFA low group $(p<0.04)$.

Taken together, these data suggest that whether body composition is expressed as BMI units, percentage of body fatness or waist circumference, the group at greatest risk for higher BP, or increased serum triglycerides, is the UFAhigh group.

Interaction between birthweight and current height In contrast to the previous analyses, expression of the various components of the metabolic syndrome was not dependent on current height or the interaction between current or attained height and birthweight. This is despite the fact that the AFA-high group was heavier than the other three groups and had significantly higher percentage of body fat, and waist circumference $(p<0.01)$ than both UFA groups.

Birth, maternal and demographic differences in phenotype groups We subsequently examined whether the differences in metabolic and BP data described above could be related to differences in birth or maternal characteristics.

Irrespective of whether the phenotypes were defined according to current BMI, generalised fatness or body fat distribution (Table 5), the UFA and AFA groups demonstrated consistently and significantly different birth characteristics (including length, ponderal index, and placental weight $[p<0.008]$ ) (Table 6). The AFA-high group also had a small, but significantly greater mean birthweight and pla-

Table 5 Current anthropometric characteristics (mean \pm SD) of the cohort

\begin{tabular}{|c|c|c|c|c|c|}
\hline & \multicolumn{2}{|c|}{ UFA $(n=73)$} & \multicolumn{2}{|c|}{ AFA $(n=64)$} & \multirow{2}{*}{$\frac{p \text { (group) }}{p(\operatorname{sex})}$} \\
\hline & Men & Women & Men & Women & \\
\hline $\begin{array}{l}\text { Weight } \\
(\mathrm{kg})\end{array}$ & $4 \pm 10.1$ & $54.0 \pm 8.8$ & $64.7 \pm 8.8$ & $62.3=$ & $\begin{array}{l}p=0.0006 \\
p=0.05\end{array}$ \\
\hline $\begin{array}{l}\text { Height } \\
(\mathrm{m})\end{array}$ & $1.69 \pm 0.08$ & $1.56 \pm 0.06$ & $1.73 \pm 0.08$ & $1.59 \pm 0.05$ & $\begin{array}{l}p=0.004 \\
p=0.0001\end{array}$ \\
\hline $\begin{array}{l}\text { BMI } \\
\left(\mathrm{kg} / \mathrm{m}^{2}\right)\end{array}$ & $20.6 \pm 2.7$ & $22.3 \pm 3.7$ & $21.7 \pm 2.4$ & $24.6 \pm 5.4$ & $\begin{array}{l}p=0.015 \\
p=0.001\end{array}$ \\
\hline $\begin{array}{l}\text { Percentage } \\
(\%) \text { of } \\
\text { body fat }\end{array}$ & $18.4 \pm 4.8$ & $28.8 \pm 4.8$ & $21.0 \pm 4.4$ & $30.2 \pm 4.6$ & $\begin{array}{l}p=0.014 \\
p=0.0001\end{array}$ \\
\hline $\begin{array}{l}\text { Waist } \\
(\mathrm{cm})\end{array}$ & $72.9 \pm 8.5$ & $69.8 \pm 7.7$ & $76.3 \pm 7.0$ & $74.7 \pm 11.3$ & $\begin{array}{l}p=0.009 \\
p=0.126\end{array}$ \\
\hline
\end{tabular}

There were no significant group by sex interaction effects 
Table 6 Newborn and maternal characteristics in study sample of full-term offspring of prima gravid women, expressed as mean $\pm \mathrm{SD}$

\begin{tabular}{lcc}
\hline & UFA $(n=73)$ & AFA $(n=64)$ \\
\hline Newborns & & \\
Birthweight $(\mathrm{kg})$ & $2.35 \pm 0.22^{\mathrm{a}}$ & $3.05 \pm 0.21$ \\
Length $(\mathrm{cm})$ & $46.0 \pm 1.7^{\mathrm{a}}$ & $49.0 \pm 1.6$ \\
Ponderal index $\left(\mathrm{kg} / \mathrm{m}^{3}\right)$ & $24.0 \pm 1.9^{\mathrm{a}}$ & $26.0 \pm 1.9$ \\
Placental weight $(\mathrm{g})$ & $486.0 \pm 55.3^{\mathrm{a}}$ & $553.2 \pm 78.7$ \\
Maternal characteristics & & \\
Weight $(\mathrm{kg})$ & $58.0 \pm 7.3^{\mathrm{a}}$ & $67.2 \pm 8.0$ \\
Height $(\mathrm{m})$ & $1.53 \pm 0.08^{\mathrm{b}}$ & $1.56 \pm 0.06$ \\
BMI $\left(\mathrm{kg} / \mathrm{m}^{2}\right)$ & $24.9 \pm 2.6^{\mathrm{a}}$ & $27.5 \pm 3.4$ \\
\hline${ }^{\mathrm{a}} p<0.001$ & & \\
${ }_{p} p=0.06$ & &
\end{tabular}

cental weight than the AFA-low group $(p<0.05)$. The UFAhigh and UFA-low groups, however, did not differ with respect to any birth or maternal characteristic. In contrast, the UFA-low mothers had a significantly lower BMI than the mothers of the two AFA groups $(p<0.01)$. Maternal smoking and alcohol intake during pregnancy, age and height did not differ between any of the groups.

When the phenotype was defined by attained height, once again, all birth characteristics were significantly higher in the AFA than the UFA groups ( $p$ values, all at least $<0.01$ ) and there was no effect of current height in any group. There were also no inter-group differences in maternal age, smoking or alcohol intake during pregnancy. The mothers of the UFA-low group were, however, significantly shorter than the mothers of the other three groups $(p<0.01)$ and the mothers of both UFA groups weighed less than those of the AFA group ( $p$ values, all at least $<0.01$ ).

\section{Discussion}

The major findings of this study are the following: (1) Subjects who were of low birthweight (UFA), but above the median at 20 years for BMI, body fat or waist circumference had significantly higher levels of systolic BP (and for fatness, diastolic BP), lipids (triglycerides, total cholesterol or LDL cholesterol) and insulin resistance measured by either fasting insulin or HOMA IR than those who were UFA but below the median for the respective anthropometric measures. (2) However, when the interaction between low birthweight and current size, as determined by height, was examined, none of these metabolic and BP effects were replicated. (3) Despite similar levels of current BMI, body fat and waist circumference in the respective above median or high groups, those who were UFA had higher systolic BP and triglycerides (BMI and waist) and both systolic and diastolic BP (body fat) than the AFA group. (4) The metabolic and BP levels were similar regardless of birthweight in the below-median groups (low).

These findings are notable for their dependence on the accumulation of weight or adipose tissue, regardless of site, but not attained height for the expression of the well- recognised metabolic and $\mathrm{BP}$ sequelae associated with low birthweight. They are also notable for the observed impact of low birthweight on these outcomes in 20-year-old adults with greater degrees of weight and adiposity. The difference in outcome between the two UFA groups could not be explained by differences in birth or maternal characteristics, socio-economic status at birth or at 20 years as assessed by level of education achieved by the subjects.

Amplification of the low birthweight effect on cardiovascular risk factors by greater weight gain in childhood and adult obesity is well recognised [4, 12, 14, 15, 17-19]. In this study, waist circumference, as a marker for abdominal fat distribution and fat mass, as a marker of general fat distribution, had similar associations with the cardiovascular risk factors. This is contrary to current evidence that visceral fat is a better marker of insulin resistance and cardiovascular risk than generalised fat [32]. Possible explanations for our findings include the fact that waist circumference reflects visceral, as well as deep and superficial subcutaneous fat. The deep subcutaneous fat has similar associations with insulin resistance as does visceral fat [33]. In unpublished data from our cohort, visceral fat measured by CT scan correlated well with both generalised fat measured by percentage of body fat $(r=0.64$, for men, and $r=0.61$ for women) and with CT-determined subcutaneous fat $(r=0.88$ for men and $r=0.81$ for women). In addition, this cohort, still in their twenties, has not yet demonstrated the centralisation of fat that is typically associated with increasing age.

The association between height or skeletal catch-up growth and components of the insulin resistance syndrome have been variable. The lack of effect of current height on cardiovascular risk factors demonstrated in our study supports in part, the findings of Bavdekar et al. [17] in Indian children. Those children who were light at birth but taller at the age of 8 years did not have increased BP, triglycerides or total cholesterol, however, they were more insulin resistant than those children who were shorter [17]. On the other hand, a number of studies have found that skeletal growth has a modulatory effect on the relationship between birthweight and systolic BP [6]. In subjects with intrauterine growth retardation and greater growth rate expressed as attained height relative to birthweight at 7 or 18 years, systolic BP was higher. An association between systolic BP and the difference in height between subjects at the age of 33 years and maternal height, as well as, the rate of fetal growth, has also been described. Further, in men over the age of 50 years, the relationship between hypertension and birthweight was strongest in those who were above median height with a BMI in the upper half of the distribution [6].

The last report suggests a potential interaction between height and weight in the relationship between birthweight and BP, This has particular relevance to the present study, as the UFA adults who were above the current median for height did not demonstrate an increase in any measure of weight or fat accumulation relative to the UFA group who were below the median for height. On the other hand the observation that height and fat mass were independent predictors of insulin resistance in the 8-year-old Indian chil- 
dren does suggest that skeletal growth has an effect on some parameters of the metabolic syndrome, at the least, in that community [17]. Attained height reflects a complex interaction between growth restriction in utero (for whatever reason), childhood nutrition, and parental height (growth potential). Therefore, it is not surprising that the relationship between height at any age and the components of the insulin resistance syndrome are inconsistent, as, at the very least, the causes and patterns of restricted fetal growth may differ.

What are the putative mechanisms underlying the associations between low birthweight and the cardiovascular risk factors and the profound and differential impact of current size (measures of fatness and attained height) on these associations? It has been postulated that genetic factors may play a role in the relationship between birthweight and the adult onset chronic diseases [34-41]. What is unclear, however, is the extent to which genetic factors may impact both on birthweight and subsequent fat accrual in childhood, and the adult outcomes.

Recent evidence suggests an association between a polymorphism in the promoter region of the $I G F-1$ gene and low birthweight, as well as postnatal weight gain [41]. In a previous report, the same polymorphism was associated with increased risk of type 2 diabetes, and myocardial infarction, diminished insulin-secreting capacity and reduced adult height [40]. Interestingly, reduced insulin secretion has rarely been found underlying the glucose tolerance associated with low birthweight [7]. Thus, it is unlikely that an $I G F-1$ polymorphism is the mechanism underlying the relationships between birthweights, subsequent growth and the chronic disease phenotype in the majority of cohorts. Another possible explanation is that programming of neurohormonal axes which are known to impact on birthweight, may alter responsiveness to environmental influences, thereby affecting subsequent weight gain and fat distribution, and ultimately culminating in these cardiovascular sequelae [42, 43].

The limitations of this study include the relatively small number of original participants that were traced and studied. A potential source of bias is that those subjects traced could have differed from those not traced. However, there is no evidence that this was the case and no reason to believe that the relationships identified would have differed between these two groups. An additional limitation is the small sample size, particularly evident when the birthweight and median anthropometric groups were further separated by sex as seen in the tables of current anthropometry. Consequently, with the exception of the comparisons in anthropometry, the analyses were not performed by sex, but by correcting for sex where this was relevant.

In conclusion, the questions at this stage are whether offspring that demonstrate the detrimental effects of subsequent adiposity (1) represent a different fetally determined phenotype than those who do not, (2) are the sole consequence of their postnatal and childhood environments or (3), as these data support, albeit in an admittedly small sample, are the product of the interaction between these two factors. The answers are not clear at present. This is particularly relevant in transitional populations in which erratic food security is common. Such a situation may result in periods of deprivation associated with stunting, being followed by times of plenty with the subsequent development of obesity. Therefore, the development of health policy concerning early life origins of adult disease requires a better characterisation of both the causes of low birthweight, and the critical periods and modulating factors determining both attained height and adiposity in adulthood. What is clear is that in each case, subsequent adiposity places all individuals at increased risk of the sequelae of the metabolic syndrome.

Acknowledgements This study was funded by the Nestlé Foundation, the South African Sugar Association, the Medical Research Council of South Africa, and the Nellie Atkinson and Harry Crossley Staff Research Funds of the University of Cape Town, as well as by a programme grant from the Wellcome Trust and the UK MRC.

\section{References}

1. Barker DJP, Osmond C, Golding J, Kuh D, Wadsworth ME (1989) Growth in utero, blood pressure in childhood and adult life and mortality from cardiovascular disease. BMJ 298:564-567

2. Hales CN, Barker DJP, Clark PMS et al (1991) Fetal and infant growth and impaired glucose tolerance at age 64. BMJ 303: 1019-1022

3. Barker DJP, Hales CN, Fall CHD, Osmond C, Phipps K, Clark PMS (1993) Type 2 (non-insulin dependent) diabetes mellitus, hypertension and hyperlipidaemia (syndrome $\mathrm{X}$ : relation to reduced fetal growth). Diabetologia 36:62-67

4. Valdez R, Athens MA, Thompson GH, Bradshaw BS, Stern MP (1994) Birthweight and adult health outcomes in a biethnic population in the USA. Diabetologia 37:624-631

5. Barker DJP (1995) Fetal origins of coronary heart disease. BMJ 311:171-174

6. Huxley RR, Shiell AW, Law CM (2000) The role of size at birth and postnatal catch-up growth in determining systolic blood pressure: a systematic review of the literature. J Hypertens 18:815-831

7. Newsome CA, Shiell AW, Fall CHD, Phillips DIW, Shier R, Law CM (2003) Is birth weight related to later glucose and insulin metabolism - a systematic review. Diabet Med 20:339348

8. Levitt NS, Steyn K, Lambert EV et al (1999) Modifiable risk factors for type 2 diabetes mellitus in a periurban community in South Africa. Diabet Med 16:946-950

9. Steyn K, Jooste P, Fourie JM, Parry CDH, Rossouw JE (1986) Hypertension in the coloured population of the Cape Peninsula. $\mathrm{S}$ Afr Med J 69:165-169

10. Louw HH, Khan MB, Woods DL, Power M, Thompson MC (1995) Perinatal mortality in the Cape Province, 1989-1991. S Afr Med J 85:352-355

11. Levitt NS, Lambert EV, Woods D, Hales CN, Andrew R, Seckl JR (2000) Impaired glucose tolerance and elevated blood pressure in low birth weight, nonobese, young South African adults: early programming of cortisol axis. J Clin Endocrinol Metab 85:4611-4618

12. Lithell HO, McKeigue PM, Berglund L, Mohsen R, Lithell U-B, Leon DA (1996) Relation of size at birth to non-insulin dependent diabetes and insulin concentrations in men aged 50-60 years. BMJ 312:406-410

13. Whincup PH, Cook DG, Adshead F et al (1997) Childhood size is more strongly related than size at birth to glucose and insulin levels in 10-11-year-old children. Diabetologia 40:319-326 
14. Leon DA, Koupilova I, Lithell HO et al (1996) Failure to realise growth potential in utero and adult obesity in relation to blood pressure in 50 year old Swedish men. BMJ 312:401-406

15. McKeigue PN, Lithell HO, Leon DA (1998) Glucose tolerance and resistance to insulin stimulated glucose uptake in men aged 70 years in relation to size at birth. Diabetologia 41:1133-1138

16. Eriksson JG, Forsen T, Tuomilehto S, Winter PD, Osmond C, Barker DJ (1999) Catch up growth in childhood and death from coronary heart disease: longitudinal study. BMJ 318:427-431

17. Bavdekar A, Yajnik CS, Fall CHD et al (1999) Insulin resistance syndrome in 8-year-old Indian children. Diabetes 48:2422-2429

18. Crowther NJ, Cameron N, Trusler J, Gray IP (1998) Association between poor glucose tolerance and rapid postnatal weight gain in seven-year-old children. Diabetologia 41:1163-1167

19. Yajnik CS (2001) The insulin resistance epidemic in India: fetal origins, later lifestyle, or both? Nutr Rev 59:1-9

20. Forsen T, Eriksson J, Tuomilehto J, Reunanen A, Osmond C, Barker D (2000) The fetal and childhood growth of persons who develop type 2 diabetes. Ann Intern Med 113:176-182

21. Walker SP, Gaskin P, Powell CA et al (2001) The effects of birth weight and postnatal linear growth retardation on blood pressure at age 11-12 years. J Epidemiol Community Health 55:394-398

22. Eriksson JG, Forsen T, Tuomilehto J, Jaddoe VWV, Osmond C, Barker DJP (2002) Effects of size at birth and childhood growth and the insulin resistance syndrome in elderly individuals. Diabetologia 45:342-348

23. Eriksson JG, Forsen T, Tuomilehto J, Osmond C, Barker DJP (2003) Early adiposity rebound in childhood and risk of type 2 diabetes in adult life. Diabetologia 46:190-194

24. Soto N, Bazaes RA, Pena V et al (2003) Insulin sensitivity and secretion are related to catch-up growth in small-for-gestational-age infants at age 1 year: results from a prospective cohort. Clin Endocrinol Metab 88:3645-3650

25. Bhargava SK, Sachdev HS, Fall CHD et al (2004) Relation of serial changes in childhood body-mass index to impaired glucose tolerance in young adulthood. N Engl J Med 350:865-875

26. Dubowitz L, Dubowitz V, Goldberg C (1970) Clinical assessment of gestational age in the newborn infant. J Pediatr 77: $1-10$

27. Durnin JVGA, Wormersely J (1973) Body fat assessment from total body density and its estimation from skin-fold thickness measurement on 481 men and women aged 16-72 years. Br J Nutr 32:77-97

28. Matthews DR, Hosker JP, Rudenski, AS, Naylor BA, Treacher DF, Turner RC (1985) Homeostasis model assessment: insulin resistance and $\beta$ cell function from fasting glucose and insulin concentrations in man. Diabetologia 28:412-419

29. Phillips DIW, Clark PMS, Hales CN, Osmond C (1994) Understanding oral glucose tolerance: comparison of glucose or insulin measurements during oral glucose tolerance test with specific measurements of insulin resistance and insulin secretion. Diabetic Med 11:286-292

30. Sobey WJ, Beer SF, Carrington CA et al (1989) Sensitive and specific two-site immunoradiometric assays for human insulin, proinsulin, 65-66 split and 32-33 split proinsulins. Biochem J 260:535-541
31. Leger J, Lévy-Marchal C, Bloch J et al (1997) Reduced final height and indications for early development of insulin resistance in a 20 year old population born with intrauterine growth retardation. BMJ 315:341-347

32. Kahn SE, Prigeon RL, Schwartz RS, et al (2001) Obesity, body fat distribution, insulin sensitivity and islet $\beta$-cell function as explanations for metabolic diversity. J Nutr 131:354S-360S

33. Kelley DE, Thaete FL, Troost F, Huwe T, Goodpaster BH (2000) Subdivisions of subcutaneous abdominal adipose tissue and insulin resistance. Am J Physiol Endocrinol Metab 278: E941-E948

34. Ong KKL, Phillips DI, Fall C et al (1999) The insulin gene VNTR, type 2 diabetes and birth weight. Nature Genet 21:262 263

35. Cambien F, Leger J, Mallet C, Levy-Marchai C, Collin D, Czernichow P (1998) Angiotensin I-converting enzyme gene polymorphism modulates the consequences of in utero growth retardation on plasma insulin in young adults. Diabetes 47:470475

36. Hattersley AT, Beards F, Ballantyne E, Appleton M, Harvey R, Ellard S (1998) Mutations in the glucokinase gene of the fetus result in reduced birth weight. Nature Genet 19:268-270

37. Rasmussen SK, Urhammer SA, Jensen JN, Hansen T, BorchJohnsen K, Pedersen O (2000) The -238 and $-308 \mathrm{G} \rightarrow \mathrm{A}$ polymorphisms of the tumor necrosis factor $\alpha$ gene promotor are not associated with features of the insulin resistance syndrome or altered birth weight in Danish Caucasians. J Clin Endocrinol Metab 85:1731-1734

38. Almind K, Ahlgren MG, Hansen T, Urhammer SA, Clausen JO, Pedersen O (1999) Discovery of a $\mathrm{Met}^{300}$ Val variant in Shc and studies of its relationship to birth weight and length, impaired insulin secretion, insulin resistance, and type 2 diabetes mellitus. J Clin Endocrinol Metab 84:2241-2244

39. Rasmussen SK, Urhammer SA, Hansen T et al (2000) Variability of the insulin receptor substrate-1, hepatocyte nuclear factor$1 \alpha(\mathrm{HNF}-1 \alpha), \mathrm{HNF}-4 \alpha$, and HNF- $6 \alpha$ genes and size at birth in a population-based sample of young Danish subjects. J Clin Endocrinol Metab 85:2951-2953

40. Vaessen N, Janssen JA, Heutink P et al (2002) Association between genetic variation in the gene for insulin-like growth factor-1 and low birth weight. Lancet 359:1036-1037

41. Vaessen N, Heutink P, Janssen JA et al (2001) A polymorphism in the gene for IGF-1: functional properties and risk for type 2 diabetes and myocardial infarction. Diabetes 50:637-642

42. Phillips DI (2001) Programming of adrenocortical function and the fetal origins of adult disease. J Endocrinol Invest 24:742746

43. Seckl JR (2001) Glucocorticoid programming of the fetus: adult phenotypes and molecular mechanisms. Mol Cell Endocrinol 185:61-71 